\title{
Activity and Durability of Iridium Nanoparticles in the Oxygen Evolution Reaction
}

\author{
Shaun M. Alia, ${ }^{a}$ Brian Rasimick,,${ }^{b, *}$ Chilan Ngo, ${ }^{\mathrm{c}}$ K. C. Neyerlin, ${ }^{\mathrm{a}}$ Shyam S. Kocha, ${ }^{\mathrm{a}, *}$ \\ Svitlana Pylypenko, ${ }^{\mathrm{c}}$ Hui Xu, ${ }^{\mathrm{b}}$ and Bryan S. Pivovar ${ }^{\mathrm{a}, *, \mathrm{z}}$ \\ ${ }^{a}$ Chemical and Materials Science Center, National Renewable Energy Laboratory, Golden, Colorado 80401, USA \\ ${ }^{b}$ Giner, Inc., Newton, Massachusetts 02466, USA \\ ${ }^{c}$ Department of Chemistry, Colorado School of Mines, Golden, Colorado 80401, USA
}

\begin{abstract}
Unsupported iridium (Ir) nanoparticles, that serve as standard oxygen evolution reaction (OER) catalysts in acidic electrolyzers, were investigated for electrochemical performance and durability in rotating disk electrode (RDE) half-cells. Fixed potential holds and potential cycling were applied to probe the durability of Ir nanoparticles, and performance losses were found to be driven by particle growth (coarsening) at moderate potential ( 1.4 to $1.6 \mathrm{~V}$ ) and Ir dissolution at higher potential ( $\geq 1.8 \mathrm{~V}$ ). Several different commercially available samples were evaluated and standardized conditions for performance comparison are reported. The electrocatalyst RDE results have also been compared to results obtained for performance and durability in electrolysis cells.

(c) The Author(s) 2016. Published by ECS. This is an open access article distributed under the terms of the Creative Commons Attribution Non-Commercial No Derivatives 4.0 License (CC BY-NC-ND, http://creativecommons.org/licenses/by-nc-nd/4.0/), which permits non-commercial reuse, distribution, and reproduction in any medium, provided the original work is not changed in any way and is properly cited. For permission for commercial reuse, please email: oa@electrochem.org. [DOI: 10.1149/2.0151611jes] All rights reserved.
\end{abstract}

Manuscript submitted May 19, 2016; revised manuscript received July 1, 2016. Published July 15, 2016. This was Paper 1455 presented at the Phoenix, Arizona, Meeting of the Society, October 11-15, 2015. This paper is part of the JES Focus Issue on Electrolysis for Increased Renewable Energy Penetration.

Hydrogen is a major commodity chemical with approximately $2 \%$ of U. S. used energy going through a hydrogen pathway, primarily for ammonia production (agriculture) and the upgrading of crude oil (transportation). The majority of hydrogen in the US is produced from natural gas by steam methane reformation. ${ }^{1}$ While electrochemical water splitting currently represents a small percentage of hydrogen production, it is expected to have a growing role as costs decrease. ${ }^{2}$ Although the commercial competitiveness of electrolysis is currently limited by feedstock costs, catalyst cost and durability will become increasingly important as electrolyzers move toward low cost, intermittent, renewable sources of electricity such as wind and solar. ${ }^{3,4}$ Acidic electrolyzers typically use iridium (Ir) in the oxygen evolution reaction (OER) as this material exhibits both reasonable activity and stability. ${ }^{5}$ Platinum and ruthenium have also been investigated as alternatives. Platinum, however, requires a higher overpotential (lower efficiency) and ruthenium has durability (dissolution) concerns. ${ }^{6-8}$

Efforts to develop improved OER catalysts for acidic electrolyzers typically focus on supporting Ir oxide on titania ${ }^{9-13}$ or alloying Ir with platinum, ruthenium, or other transition metal oxides ${ }^{14-23}$ to improve durability and performance. Density functional theory studies have correlated trends in the OER activity of metal oxides to the adsorption energies of surface oxygen species, suggesting future directions for improving OER catalysts. ${ }^{24}$ Strasser et al. also examined the intrinsic activity of Ir, platinum, and ruthenium polycrystalline metals and nanoparticles in rotating disk electrode (RDE) half-cells, using carbon monoxide to determine catalyst surface areas. ${ }^{6}$ Efforts exploring OER catalysts, however, pale in comparison to the efforts expended in the pursuit of fuel cell catalysts for the oxygen reduction reaction (ORR). Specifically, the fuel cell community has established baselines and protocols for the performance and durability of ORR catalysts. ${ }^{25-28}$ No such protocols or baselines currently exist for OER catalysts.

This study presents data from several different commercial suppliers of unsupported and supported Ir and Ir oxide catalysts, and investigates the intrinsic activity of Ir in RDE half-cells, evaluating both performance and durability while presenting the data under standardized conditions. The modes of losses for Ir nanoparticles under specific testing protocols are presented and evaluated, and then compared to performance and durability found in single-cell, electrolysis

\footnotetext{
*Electrochemical Society Member
}

${ }^{\text {z}}$ E-mail: bryan.pivovar@nrel.gov testing. ${ }^{29}$ These types of studies and results are critical for establishing baseline performance and protocols for evaluating OER catalysts within the electrocatalysis community.

\section{Experimental}

A variety of Ir catalysts were surveyed for their OER activity, including Ir blacks, Ir oxide, carbon-supported Ir, titania-supported Ir oxide, and polycrystalline Ir. Ir blacks were from Johnson Matthey (product number C2026/160000, $\geq 93.0$ wt\% Ir), Alfa Aesar (product number 47150, 99.95\% Ir), Premetek Co. (product number P40V010), and Umicore (not commercial product, batch number 0363/00-I4, 98.82\% Ir). Ir oxide was from Alfa Aesar (product number 43396, $\geq 84.5 \%$ Ir). Carbon-supported Ir (Ir/Vulcan) was from Premetek Co. (P40A200, 20\% Ir) and titania-supported Ir oxide was from Umicore (not commercial product, batch number 0821/01-D5, 73.35\% Ir). Polycrystalline Ir was from American Elements (product number IR-M-03M-D.4MMT, $\geq 99.9 \%$ Ir). Transmission electron microscopy (TEM) images of the surveyed catalysts were taken on a Philips CM200.

A standard ink contained $3.5 \mathrm{mg}$ of Ir dispersed in $7.6 \mathrm{ml}$ of water, $2.4 \mathrm{ml}$ of 2-propanol, and $40 \mu \mathrm{l}$ of Nafion (5 wt\%, Sigma Aldrich). Inks were bath sonicated for $20 \mathrm{~min}$ in ice; following sonication, $10 \mu \mathrm{l}$ aliquots were pipetted onto polished polycrystalline gold electrodes. Electrodes were optimized based on mass activity for Ir loading and Nafion content in the catalyst ink. The standard ink corresponded to an Ir electrode loading of $17.8 \mu \mathrm{g}_{\mathrm{Ir}} \mathrm{cm}_{\text {elec }}{ }^{-2}$ and a Nafion content of $0.1 \mu \mathrm{g}_{\text {Nafion }} \mathrm{mg}_{\mathrm{Ir}}{ }^{-1}$.

The Ir electrochemical surface area (ECA) was determined by mercury underpotential deposition, from the charge associated with a monolayer of mercury being desorbed from the Ir surface. Ir ECA experiments were completed in a $0.1 \mathrm{M}$ perchloric acid electrolyte containing $1 \mathrm{~mm}$ mercury nitrate. ${ }^{30,31}$ Cyclic voltammograms were performed at $20 \mathrm{mV} \mathrm{s}^{-1}$ in the potential range $0.025-0.55 \mathrm{~V}$ vs RHE. As an ECA baseline measurement, a polished polycrystalline Ir disc gave a surface roughness of 1.3 using this technique, suggesting the assumed Coulombic charge of $138.6 \mu \mathrm{C} \mathrm{cm}_{\mathrm{Ir}}{ }^{-2}$ is a reasonable estimate of charge per ECA. Ir ECAs were generally constant at Ir loadings lower than $20 \mu \mathrm{g}_{\mathrm{Ir}} \mathrm{cm}_{\text {elec }}{ }^{-2}$. ECA slightly decreased $(\sim 10 \%)$ at loadings greater than $70 \mu \mathrm{g}_{\mathrm{Ir}} \mathrm{cm}_{\text {elec }}{ }^{-2}$, potentially due to electronic isolation of a fraction of the Ir nanoparticles. Nafion in the catalyst ink also resulted in electrodes with similar activities up to $0.1 \mu \mathrm{g}_{\text {Nafion }}$ 
$\mathrm{mg}_{\mathrm{Ir}}{ }^{-1}$; at higher Nafion content, OER activities decreased. The use of a Nafion cap did not improve OER activity or durability.

Electrochemical characterization of Ir nanoparticles was performed in a RDE half-cell containing $0.1 \mathrm{M}$ perchloric acid, equipped with a polished polycrystalline gold working electrode, a gold counter electrode, and a reversible hydrogen electrode (RHE) connected to the electrochemical cell by a Luggin capillary. Working electrode rotation was controlled with a modulated speed rotator (Pine Instruments) and electrochemical measurements were taken with an Autolab PGSTAT302N potentiostat (Eco Chemie, Metrohm Autolab B. V.). Internal resistance (iR) values $(24-27 \Omega$ ) were taken with a built-in current interrupter at $1.6 \mathrm{~V}$ vs RHE; these measurements were repeated at 1.4 and $1.8 \mathrm{~V}$ vs RHE and resulted in identical values. The internal resistance correction refers to the correction between the reference electrode (Luggin tip) and working electrode. Internal resistance values were corrected for by the potentiostat in linear sweep, choronoamperometry, and accelerated stress tests. These corrections were comparable to corrections for platinum-ORR in $0.1 \mathrm{M}$ perchloric acid (21-23 $\Omega$ ); the slightly higher corrections in this study may be due to test-totest changes in cell setup or to differences in the catalyst layer. ${ }^{32}$

Electrochemical break-in of the Ir nanoparticles was completed by potential cycling 10 times from $1.2-1.8 \mathrm{~V}$ vs RHE at $100 \mathrm{mV}$ $\mathrm{s}^{-1}$. Linear polarization curves were completed in the potential range $1.2-2.0 \mathrm{~V}$ vs RHE, at $20 \mathrm{mV} \mathrm{s}^{-1}$, and a rotation speed of $2500 \mathrm{rpm}$. Catalyst activities were evaluated at $1.55 \mathrm{~V}$ vs RHE. Mass activities were defined as OER activity normalized to the mass of Ir coated on the working electrode. Site-specific activities were defined as OER activities normalized to the Ir ECA available on the working electrode.

The impact of durability test conditions was investigated by potential hold and potential cycling experiments at $2500 \mathrm{rpm}$ in a $0.1 \mathrm{M}$ perchloric acid electrolyte. Potential holds were performed at a variety of potentials $(1.4,1.5,1.55,1.6,1.8$, and $2.0 \mathrm{~V}$ vs RHE, iR corrected) over $13.5 \mathrm{~h}$, with linear sweep voltammograms taken periodically to monitor activity losses. The test duration $(13.5 \mathrm{~h})$ was used since the activity losses at a given potential significantly slowed by the end of the durability test. At elevated potential (1.8-2.0 V vs RHE), Ir dissolution consumed a significant portion of the available Ir. At moderate potential (1.4-1.6 V vs RHE), however, the dissolution rate was relatively slow at less than $0.2 \mu \mathrm{g}_{\mathrm{Ir}}(<5 \%$ of the working electrode) in $13.5 \mathrm{~h}$. Although dissolution would have continued and slowly eroded OER activity, the rate of dissolution-driven loss was slower than the initial activity decay. Potential cycling was performed for 30,000 cycles at $500 \mathrm{mV} \mathrm{s}^{-1}$, with a lower potential $1.4 \mathrm{~V}$ vs RHE and a variety of upper potentials $(1.5,1.55,1.6,1.8,2.0 \mathrm{~V}$ vs RHE, iR corrected). Linear sweep voltammograms were also taken periodically to monitor losses in OER activity. Cell voltage was auto-corrected for internal resistance, based on measured ohmic drops inside the cell.

Inductively coupled plasma-mass spectrometry (ICP-MS) measurements were taken of electrolytes following potential holds or cycles with a Thermo Scientific iCAP Q. Experiments were calibrated to a blank and three standards; electrolytes were run three times with a dwell time of $0.15 \mathrm{~s}$ and a standard deviation of less than $2 \%$ between the individual runs. Following durability, catalyst activities were evaluated at $1.55 \mathrm{~V}$ vs RHE. The mass activities were based on the mass of Ir originally coated onto the working electrode, and was not lowered to account for Ir that dissolved during testing. The site-specific activities were based on the Ir ECA determined following durability, measured by mercury underpotential deposition.

Membrane electrode assemblies (MEAs) were fabricated and tested to compare half-cell and single-cell performances. Decals for the anode $\left(0.1\right.$ or $0.4 \mathrm{mg}_{\text {Ir }} \mathrm{cm}^{-2}$, Johnson Matthey Ir black, $20 \mathrm{wt} \%$ Nafion) and cathode $\left(0.4 \mathrm{mg}_{\mathrm{Pt}} \mathrm{cm}^{-2}\right.$ Tanaka Kikinzoku Kogyo platinum on carbon, $30 \mathrm{wt} \%$ Nafion) were spray cast using an acetone/butanol carrier and later transferred to Nafion N1110 using a hot press at $175^{\circ} \mathrm{C}$ and $150 \mathrm{psi}$. The MEA was operated in Fuel Cell Technologies (FCT) $50 \mathrm{~cm}^{2}$ hardware using a platinized titanium anode flow field, a platinized titanium anode gas diffusion layer, a carbon fiber cathode gas diffusion layer, and the standard FCT graphite cathode flow field. The cell was operated at $80^{\circ} \mathrm{C}$ with water fed to the anode at a rate of approximately $300 \mathrm{~mL} \mathrm{~min}^{-1}$. No back-pressure was applied to the cell. Accelerated aging testing was conducted by alternating the cell from $1.45 \mathrm{~V}$ to $2.0 \mathrm{~V}$ every thirty seconds ( 1 cycle per minute). MEA durability tests were completed for 10,000 and 23,000 cycles, or 6.9 and 16.0 days.

\section{Results}

The content of this paper has been grouped into three parts: a survey of catalyst OER activities and durability; an examination of Ir nanoparticle durability and degradation modes; and a comparison between half-cell and single-cell performance and durability.

Catalyst survey.-Electrode coating, testing, and durability protocols were optimized with Ir black (Johnson Matthey). These protocols were systematically applied to survey several Ir catalysts for their OER activity and durability: Ir blacks from Johnson Matthey (JM Ir), Alfa Aesar (AA Ir), Premetek Co. (Pr Ir), and Umicore (Um Ir); Ir oxide from Alfa Aesar (AA $\left.\mathrm{IrO}_{2}\right)$; carbon-supported $\mathrm{Ir}$ (Ir/Vulcan) from Premetek Co. (Pr Ir/V); and titania-supported $\mathrm{Ir}$ oxide $\left(\mathrm{Ir} / \mathrm{TiO}{ }_{2}\right)$ from Umicore ( $\mathrm{Um} \mathrm{Ir} / \mathrm{TiO}_{2}$, Figure 1a, Table I). These catalysts were evaluated for OER activity at $1.55 \mathrm{~V}$ vs RHE, within the kinetic (linear) region of linear sweep voltammograms, and their ECAs and site-specific activities were determined using mercury underpotential deposition. ${ }^{31}$ Unsupported catalysts produced ECAs of $15-30 \mathrm{~m}^{2} \mathrm{~g}_{\mathrm{Ir}}{ }^{-1}$, with the exception of the Ir black from Premetek Co. which produced an ECA of approximately $50 \mathrm{~m}^{2} \mathrm{~g}_{\mathrm{Ir}}{ }^{-1}$, likely due to differences in catalyst morphology (5-10 $\mathrm{nm}$ rods versus more spherical, 20-50 nm aggregates as reflected by microscopic analysis, Figure 2). The ECA values also generally followed trends expected from the microscopy analysis and Brunauer-Emmett-Teller (BET) measurements. ${ }^{31}$

Durability testing was completed on the surveyed catalysts by applying a $1.6 \mathrm{~V}$ hold for $13.5 \mathrm{~h}$. Although durability tests with a wider
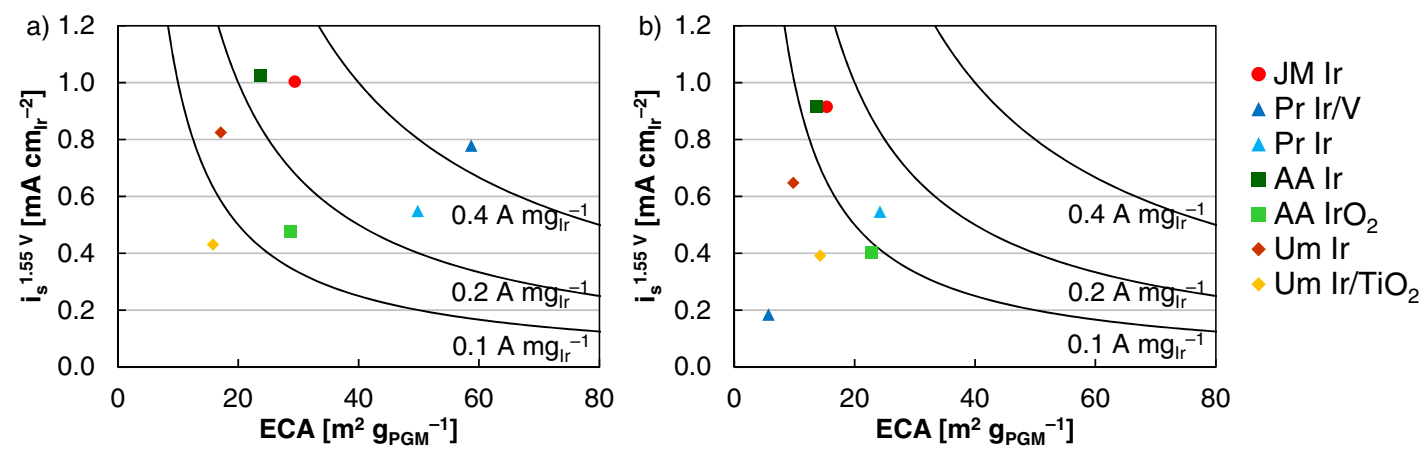

Figure 1. ECAs (x-axis) and site-specific OER activities (y-axis) at $1.55 \mathrm{~V}$ vs RHE (a) prior to and (b) following durability (1.6 V hold for 13.5 h), comparing Johnson Matthey (JM) Ir black, Premetek Co. (Pr) Ir/Vulcan (Ir/V) and Ir black, Alfa Aesar (AA) Ir black and Ir oxide (IrO $\left.\mathrm{O}_{2}\right)$, and Umicore (Um) Ir black and titania-supported Ir oxide $\left(\mathrm{Ir} / \mathrm{TiO}_{2}\right)$. Solid black lines denote constant mass activities of $0.1,0.2$, and $0.4 \mathrm{~A} \mathrm{mg}_{\mathrm{Ir}}{ }^{-1}$. 
Table I. ECAs and OER activities of examined catalysts at $1.55 \mathrm{~V}$ vs RHE prior to and following durability (1.6 V hold for $13.5 \mathrm{~h}$ ).

\begin{tabular}{|c|c|c|c|c|c|c|c|}
\hline & & \multicolumn{3}{|c|}{ Initial } & \multicolumn{3}{|c|}{ Following 1.6 V Hold } \\
\hline & & $\begin{array}{c}\text { ECA } \\
{\left[\mathrm{m}^{2} \mathrm{~g}_{\mathrm{Ir}}^{-1}\right]}\end{array}$ & $\begin{array}{c}\mathrm{i}_{\mathrm{m}}{ }^{1.55 \mathrm{~V}} \\
{\left[\mathrm{~A} \mathrm{mg}_{\mathrm{Ir}}{ }^{-1}\right]}\end{array}$ & $\begin{array}{c}\mathrm{i}_{\mathrm{s}}^{1.55 \mathrm{~V}} \\
{\left[\mathrm{~mA} \mathrm{~cm}_{\mathrm{Ir}}{ }^{-2}\right]}\end{array}$ & $\begin{array}{c}\text { ECA } \\
{\left[\mathrm{m}^{2} \mathrm{gIr}^{-1}\right]}\end{array}$ & $\begin{array}{c}\mathrm{i}_{\mathrm{m}} 1.55 \mathrm{~V} \\
{\left[\mathrm{~A} \mathrm{mg}_{\mathrm{Ir}}{ }^{-1}\right]}\end{array}$ & $\begin{array}{c}\mathrm{i}_{\mathrm{s}}{ }^{1.55 \mathrm{~V}} \\
{\left[\mathrm{~mA} \mathrm{~cm}_{\mathrm{Ir}}{ }^{-2}\right]}\end{array}$ \\
\hline AA & $\mathrm{IrO}_{2}$ & 28.7 & 0.14 & 0.48 & 22.9 & 0.09 & 0.40 \\
\hline AA & Ir & 23.6 & 0.24 & 1.03 & 13.6 & 0.12 & 0.92 \\
\hline Pr & Ir & 49.8 & 0.27 & 0.55 & 24.2 & 0.13 & 0.55 \\
\hline Pr & $\mathrm{Ir} / \mathrm{V}$ & 58.7 & 0.46 & 0.78 & 5.7 & 0.01 & 0.18 \\
\hline
\end{tabular}

range of potentials and protocols were completed in later experiments, a $1.6 \mathrm{~V}$ hold was used in this case since it produced losses similar to MEA durability tests over a shorter period of time. Following durability testing, the catalysts were evaluated for activity at $1.55 \mathrm{~V}$ vs RHE. Mass activities were calculated based on the original mass of Ir coated on the working electrode. Site-specific activities following durability testing were calculated based on the Ir ECA following durability, as determined by mercury underpotential deposition. While the surveyed catalysts all lost ECA, the losses were higher for catalysts with higher surface areas, likely because higher surface area catalysts tend to be more prone to particle aggregation and ripening (Figure $1 \mathrm{~b}$, Table I). Ir/Vulcan (Premetek Co.) was also noted as a special case, producing an ECA and OER mass activity higher than all other materials examined. Nearly all that activity was lost following durability, however, likely due to corrosion of the carbon support.

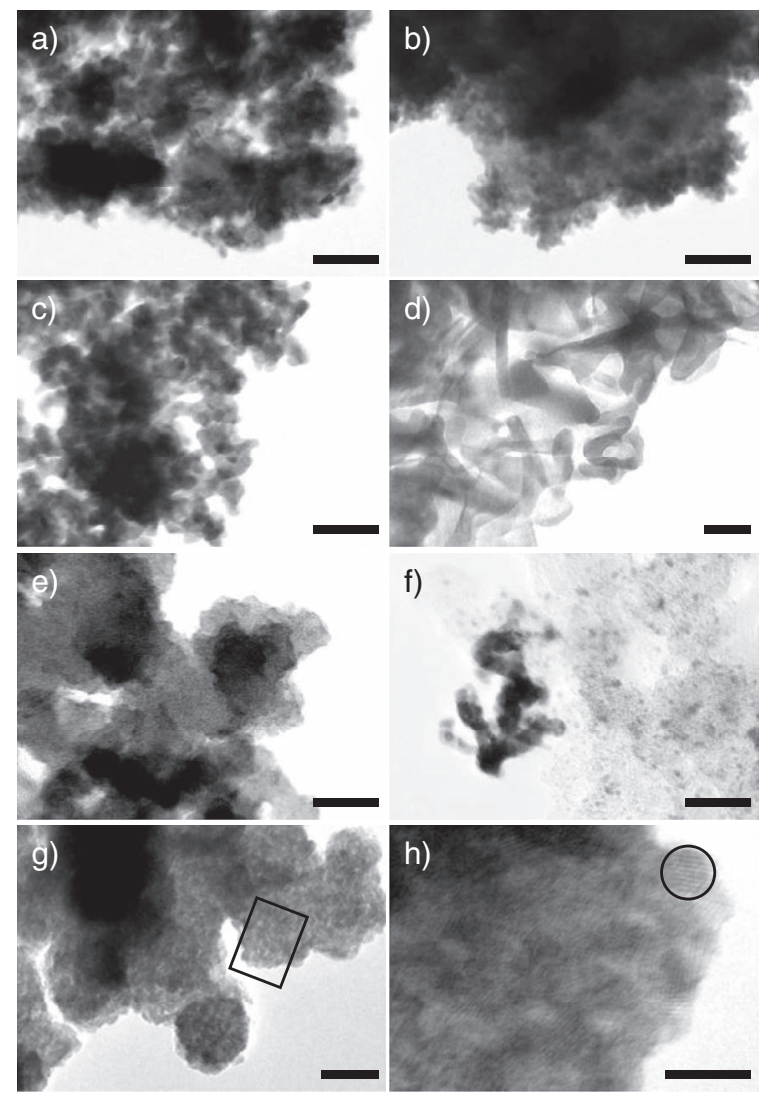

Figure 2. TEM images of Ir blacks from (a) Johnson Matthey, (b) Alfa Aesar, (c) Premetek Co., and (d) Umicore. TEM images of (e) Ir oxide (Alfa Aesar), (f) carbon-supported (Vulcan) Ir (Premetek Co.), and (g-h) titania-supported Ir oxide (Umicore). Subset (h) of titania-supported Ir oxide (Umicore) is from the boxed area in (g), showing that the large features consist of heavily aggregated $\sim 3 \mathrm{~nm}$ particles. One such particle is indicated by the circle in (h). All scale bars are $20 \mathrm{~nm}$, except (h) which has a scale bar of $5 \mathrm{~nm}$.
Iridium nanoparticle durability.-Ir black from Johnson Matthey was used for more detailed study since it was representative of other catalyst activities (Figure 1a). ${ }^{29}$ Although several catalysts were surveyed for their activity and durability, subsequent discussions focus on the Ir black from Johnson Matthey (denoted JM throughout the remainder of the text).

OER activity was examined with linear polarization curves, taken at $20 \mathrm{mV} \mathrm{s}^{-1}$ and $2500 \mathrm{rpm}$, and corrected for internal resistance in the potential range 1.2-2.0 V vs RHE (Figures 3a, 3b). Tafel plots (Figure $3 \mathrm{c}$ ) of the Ir nanoparticle (JM) polarization curves gave a kinetic (linear) response at potentials less than $1.55 \mathrm{~V}$ with a Tafel slope of $44-45 \mathrm{mV} \mathrm{dec}{ }^{-1}$. At higher potentials, transport, or the removal of oxygen bubbles from the electrode surface, became a contributing factor. At high potential, the fast generation and removal of oxygen bubbles created a transient state on the electrode surface and produced noise in the measured current (Figure 3a). Differences between linear sweep voltammograms (red line) and successive chronoamperometry experiments (blue crosses) were minimal in the kinetic region; at potentials of $1.55 \mathrm{~V}$ and above, however, the results between the two tests deviated (Figure 3b). The lower current in chronoamperometry was likely due to the elevated time spent at potential, exacerbating transport limitations. Polycrystalline Ir (blue line) also produced sitespecific activities significantly larger than Ir nanoparticles (red line, Figure $3 \mathrm{c}$ ). This phenomenon is similar to that observed in platinumORR, where extended surfaces produce site-specific activities greater than nanoparticles. ${ }^{31}$

Electrochemical aging was investigated by potential holds $(13.5 \mathrm{~h})$ and cycles $\left(30,000\right.$ cycles, $500 \mathrm{mV} \mathrm{s}^{-1}$, lower potential bound of $1.4 \mathrm{~V}$, Figure 4). For both methods, mass activity losses of approximately $50 \%$ (red squares) occurred at moderate potential $(1.5-1.6 \mathrm{~V}$, Figures $4 \mathrm{a}$ and $4 \mathrm{c}$ ). These losses were primarily due to ECA loss (green squares, Figures $4 \mathrm{~b}$ and $4 \mathrm{~d}$ ) while the site-specific activity remained nearly constant (blue squares, Figures $4 \mathrm{a}$ and $4 \mathrm{c}$ ). Although dissolution losses occurred, they were less than $5 \%$ and could not account for the observed ECA loss (Figures $4 \mathrm{e}$ and $4 \mathrm{f}$ ). At high potential $(1.8-2.0 \mathrm{~V})$, more severe losses were found to be the result of both decreasing ECA and site-specific activity. ICP-MS of electrolytes also showed a clear, approximately linear increase in Ir dissolution at higher potential, between 1.6 and $2.0 \mathrm{~V}$. At 1.8 and $2.0 \mathrm{~V}$, more Ir dissolution also occurred during potential holds than cycles, likely due to the increased time spent at elevated potential. These results suggest that high potentials are more detrimental than cycling for Ir catalyst durability. This is a noticeable difference from platinum fuel cell catalysts, where potential cycling within typical operating ranges $(0.6-1.0 \mathrm{~V})$ and repeated platinum redox is critical to accelerating platinum aggregation-based durability losses. ${ }^{33,34}$ This difference, however, is heavily influenced by the differences between fuel cell-relevant and electrolyzer-relevant test conditions. Since Ir is an oxide at electrolyzer-relevant potentials, cycling may be less critical to agglomeration-driven losses. Charge state transitions of Ir centers in electrolyzer-relevant potentials, however, may impact Ir durability under OER cycling. An Ir (IV)/(V) transition has been presented through modeling for an Ir oxide surface and through electrochemical measurements for Ir oxide nanoparticles at a 

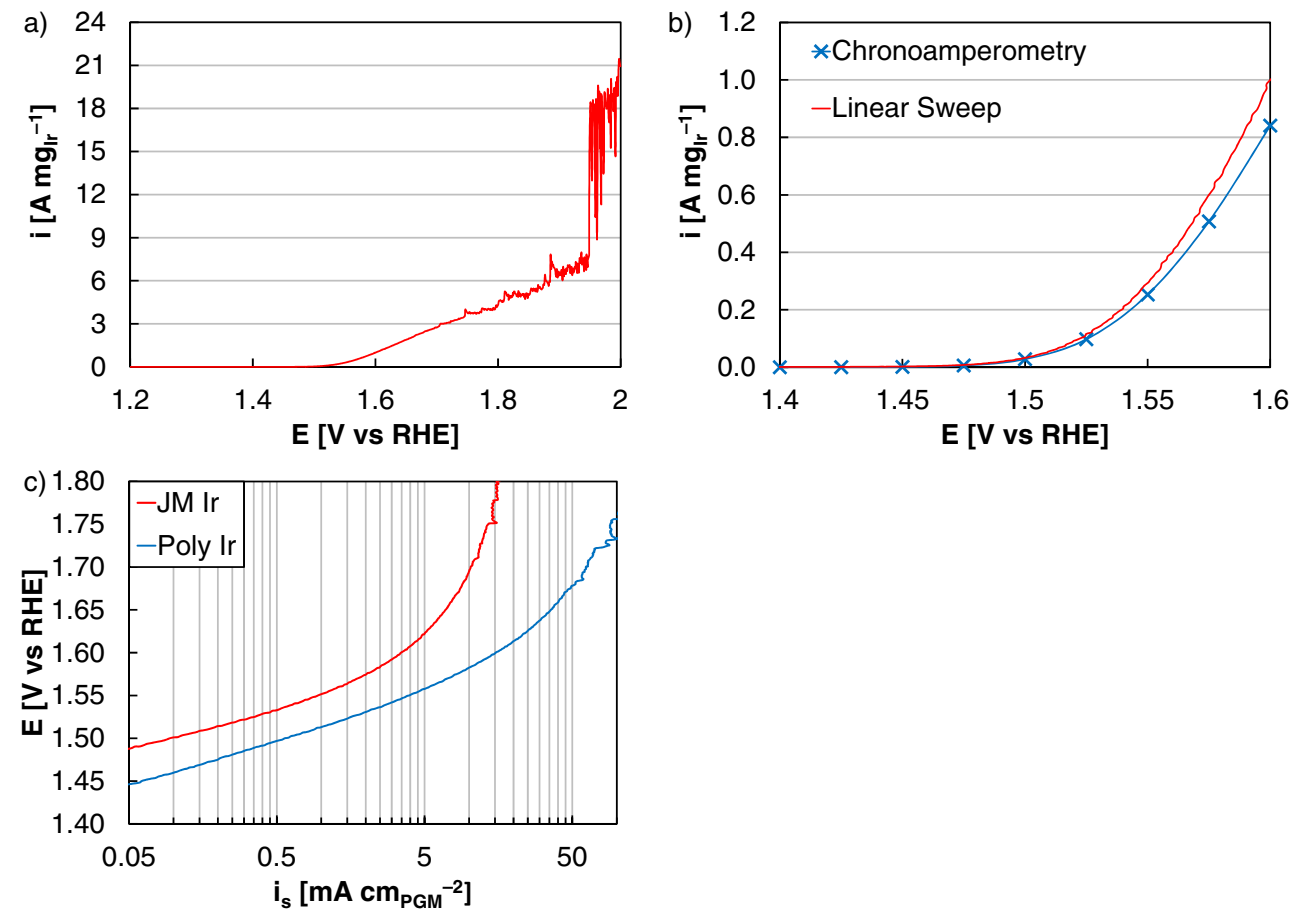

Figure 3. (a) An OER linear polarization curve of Ir nanoparticles (JM) and (b) its comparison to successive chronoamperometry experiments. (c) Tafel plots of Ir nanoparticles and a polycrystalline Ir electrode on a site-specific activity basis.
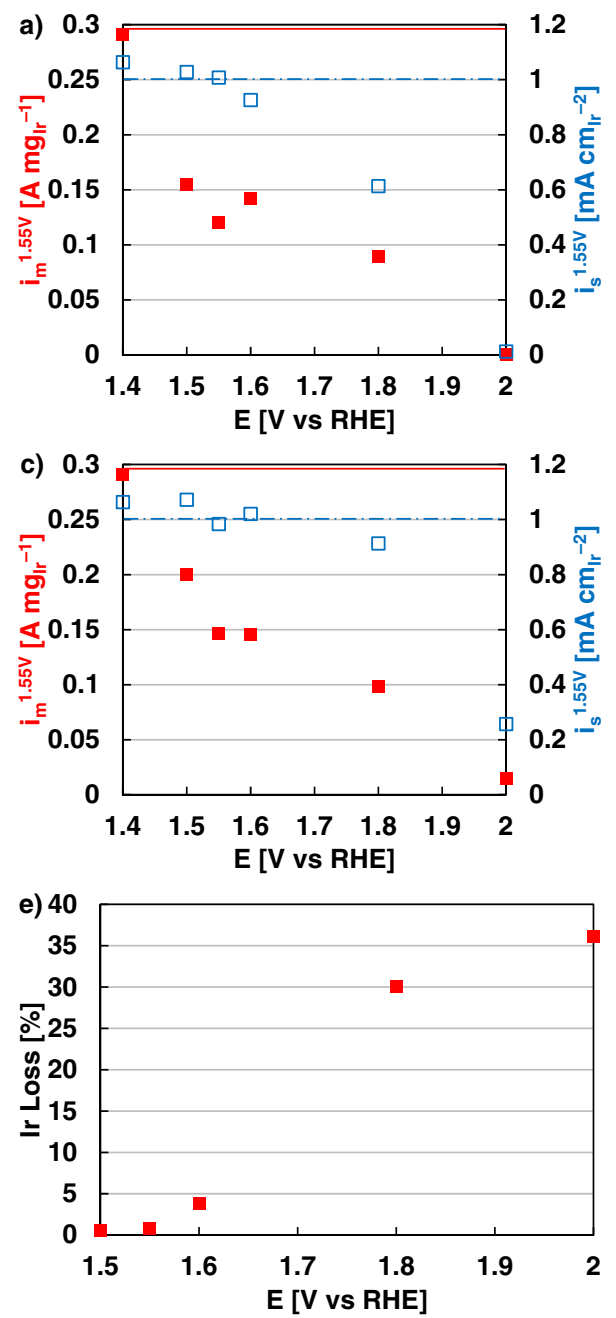

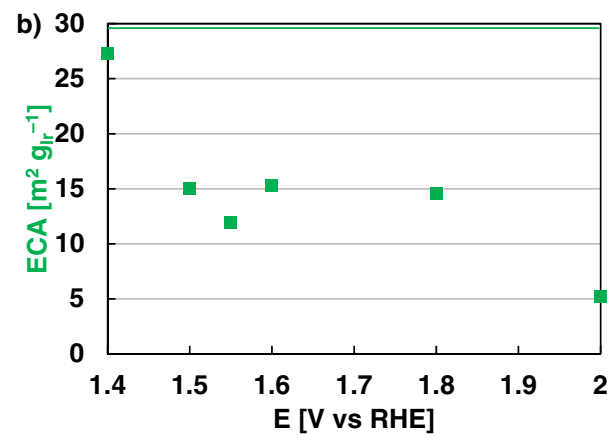

d) 30
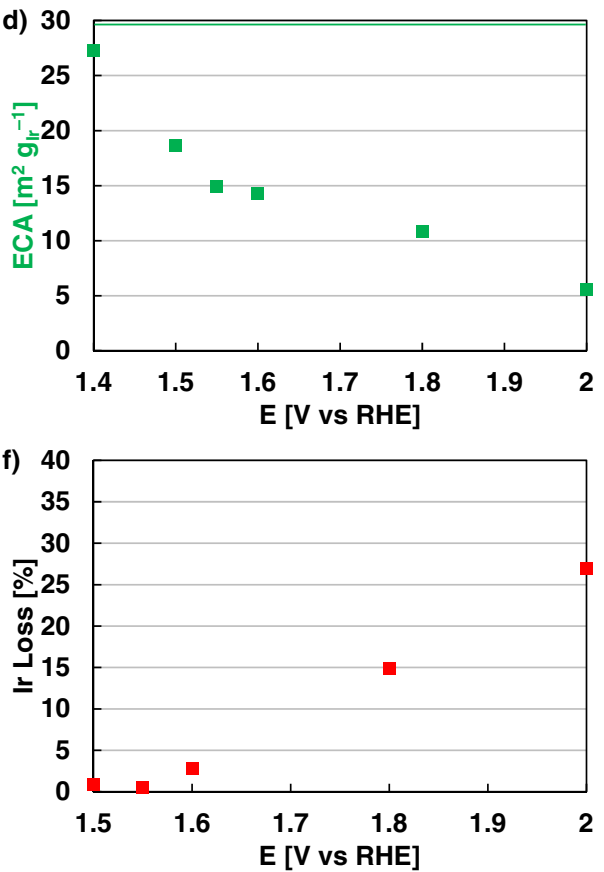

Figure 4. Mass activities, specific activities, and ECAs of Ir nanoparticles (JM) following accelerated stress tests by potential holds $(\mathrm{a}-\mathrm{b})$ and potential cycles (c-d). Potential holds $(13.5 \mathrm{~h})$ were completed at potentials specified on the $\mathrm{x}$ axis. Potential cycles $(30,000)$ were completed at $500 \mathrm{mV} \mathrm{s}^{-1}$ to a lower potential of $1.4 \mathrm{~V}$ and an upper potential specified on the $\mathrm{x}$-axis. The initial activities and ECA of the Ir nanoparticles were added as lines. Percent Ir lost by dissolution, calculated by ICP-MS results, following (e) potential holds and (f) potential cycles, with the potential specified on the $\mathrm{x}$-axis. 


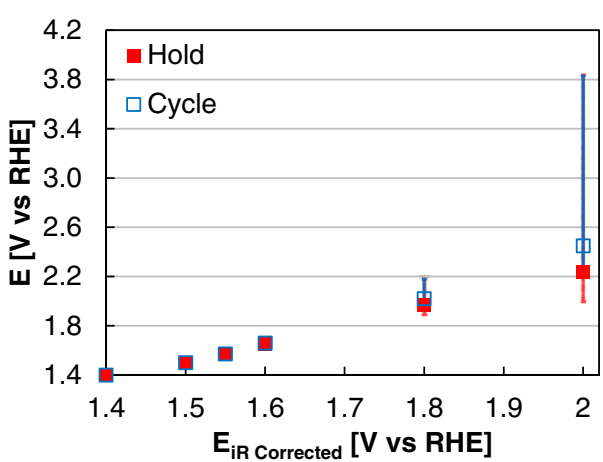

Figure 5. Comparison between the uncorrected potential (y-axis) and the potential corrected for internal resistance ( $\mathrm{x}$-axis) during accelerated stress tests. Data points correspond to the average potential (in cycles, the average upper bound potential). Error bars (red and blue vertical lines), correspond to the upper and lower limits of the uncorrected potential in the accelerated stress tests.

potential of $1.3-1.5 \mathrm{~V}^{35-37}$ The impact on agglomeration-driven losses for Ir metal nanoparticles, however, is unclear. Ir nanoparticles did not exhibit Ir oxide characteristics in cyclic voltammograms (III/IV transition) or a shoulder in OER tests (Figure 2c, IV/V transition), before or after durability. ${ }^{31,35-38}$ The impact on dissolutiondriven losses is also unclear, since only a small amount of dissolution occurred during accelerated stress tests at these potentials (Figures $4 \mathrm{e}$ and $4 \mathrm{f}$ ). In either case, potential cycling of Ir nanoparticles produced less severe losses than potential holds in durability tests at electrolyzer-relevant potentials (Figures $4 \mathrm{a}$ and $4 \mathrm{c}$ ).

Internal resistance-corrected potentials are necessary to evaluate kinetic activities and to perform uniform durability tests across catalyst types with varying performance. The local potential drop at the catalyst/electrolyte interface, however, is an important parameter. Since the uncorrected potential at the Ir catalyst is important for the observed dissolution rates, we have reported the uncorrected voltages applied as a function of the corrected voltages in durability tests by potential holds (red squares) and cycles (blue squares, Figure 5). Although the correction has a small impact at low potential, its effect becomes significant at higher potential due to the increasing current. Pourbaix has noted that Ir transitions from Ir oxide $\left(\mathrm{IrO}_{2}\right)$ to soluble forms of Ir at approximately $1.8 \mathrm{~V}$ (Figure 6) ${ }^{39}$ Internal resistance cor-

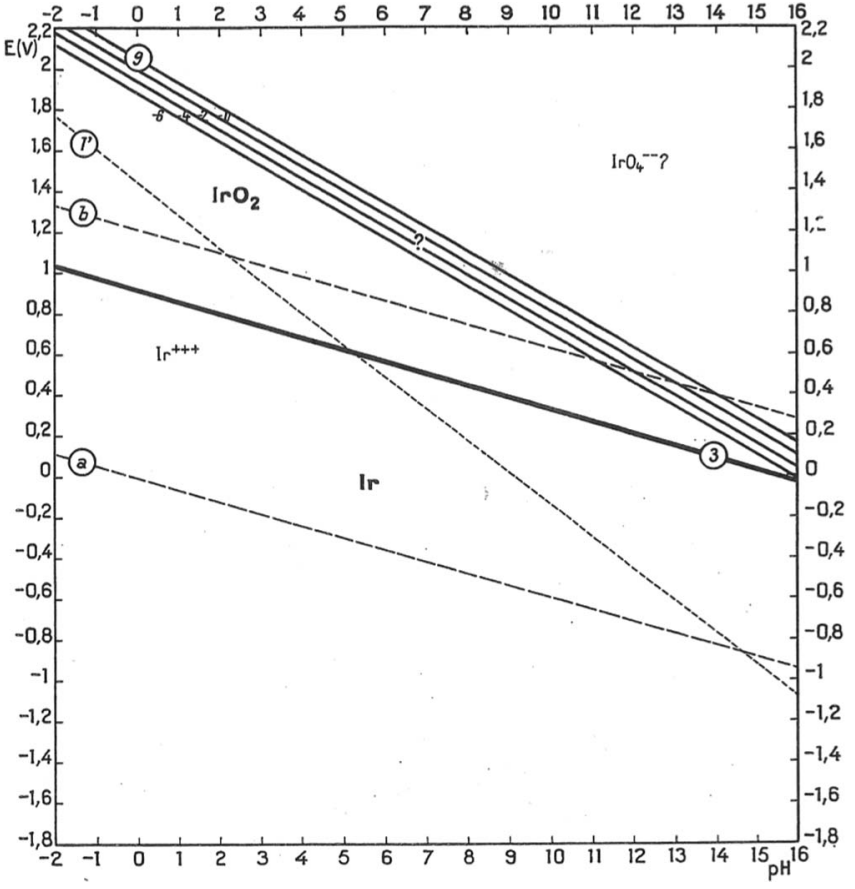

Figure 6. Pourbaix diagram for the iridium-water system at $25^{\circ} \mathrm{C}$ and its dependence on $\mathrm{pH}$ and potential. ${ }^{39}$ Reproduced with permission from NACE International, Houston, TX. All rights reserved. M. Pourbaix, Atlas of electrochemical equilibria in aqueous solutions, National Association of Corrosion Engineers, Houston, TX (1974).

rections can therefore push Ir into a soluble-favored state or accelerate Ir dissolution.

A specific concern of OER durability experiments was that the observed losses could be due to large gas generation rates detaching the catalyst layer. To ensure that ECA loss was not due to catalyst detachment, electrochemical aging tests were performed in the form of chronopotentiometry experiments, which fixed the current and gas generation rate. These experiments were performed in OER (green triangles), hydrogen peroxide oxidation (red squares, forming oxygen), and formic acid oxidation (blue circles, forming carbon dioxide, Figure 7). ${ }^{40-45}$ These tests produced gas bubbles of various sizes on the
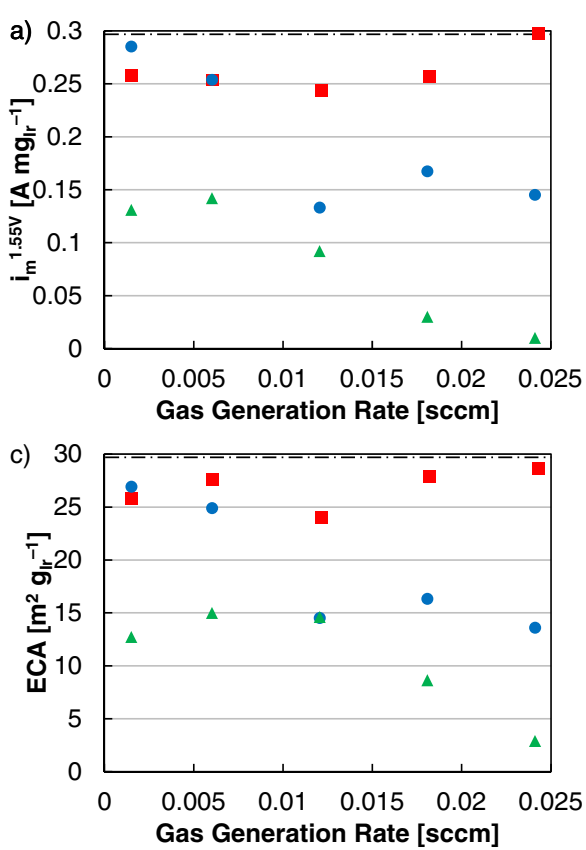

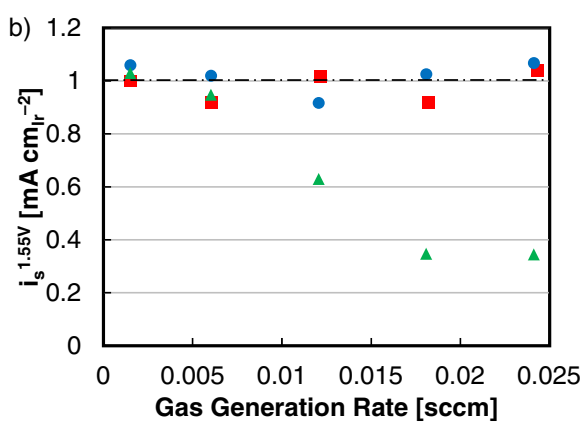

Figure 7. (a) OER mass activities, (b) OER specific activities, and (c) ECAs of Ir nanoparticles (JM) following accelerated stress tests in hydrogen peroxide oxidation $\left(\mathrm{H}_{2} \mathrm{O}_{2}\right.$, red squares), formic acid oxidation ( $\mathrm{HCOOH}$, blue circles), and OER (green triangles). The initial activities and ECA of the Ir nanoparticles were added as dotted black lines.

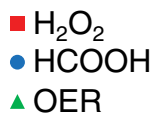



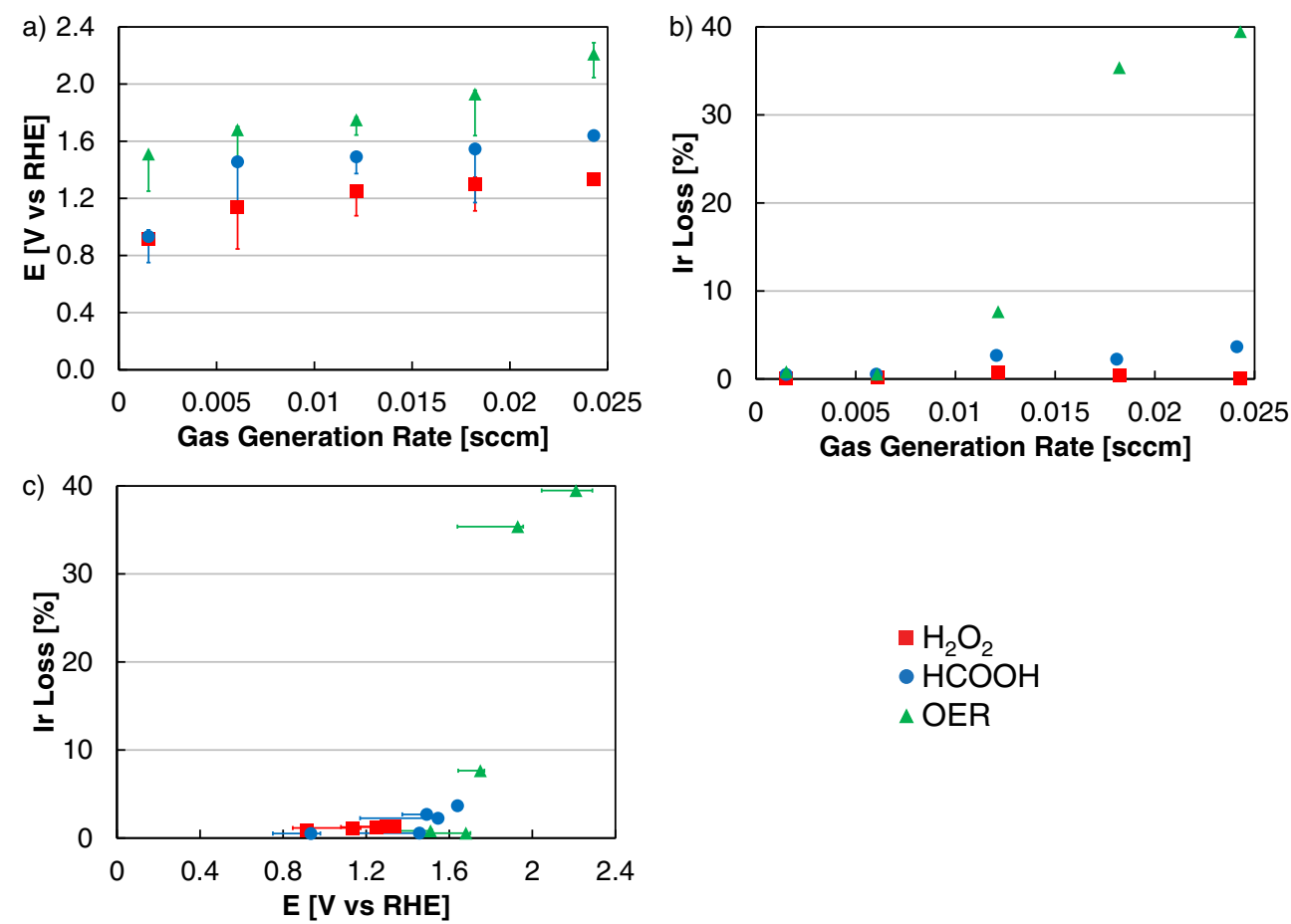

Figure 8. (a) Average potential (corrected for iR) during accelerated stress tests in hydrogen peroxide oxidation $\left(\mathrm{H}_{2} \mathrm{O}_{2}\right)$, formic acid oxidation $(\mathrm{HCOOH})$, and OER. Percent Ir lost by dissolution into the electrolyte following accelerated stress tests in hydrogen peroxide oxidation $\left(\mathrm{H}_{2} \mathrm{O}_{2}\right)$, formic acid oxidation $(\mathrm{HCOOH})$, and OER as a function of the (b) gas generation rate and (c) potential. Error bars in figure subset (a) and (c) correspond to the maximum and minimum potential of the electrode.

electrode surface. At high gas generation rates, bubbles as large as 10 $\mu l$ could periodically form and cover the electrode surface before diffusing away from the electrode. At gas generation rates of $0.02-0.03$ sccm, large bubbles covering the electrode could be formed at a rate of $2-3$ per minute. Hydrogen peroxide oxidation, formic acid oxidation, and OER occurred at different potentials. For example, a gas generation rate of $0.002-0.025 \mathrm{sccm}$ on Ir required a potential of $0.8-1.3 \mathrm{~V}$ in hydrogen peroxide oxidation, $0.8-1.7 \mathrm{~V}$ in formic acid oxidation, and $1.4-2.3 \mathrm{~V}$ in OER. The impact of potential could therefore be decoupled from that of gas generation. The gas generation rates reported ignored any specific differences in gas solubility or density (carbon dioxide, oxygen). In all cases, the initial OER activity and ECA of the Ir nanoparticles (JM) was included as a dashed line. Performance following the chronopotentiometry experiments was evaluated by mass OER activity (Figure 7a), site-specific OER activity (Figure 7b), and ECA (Figure 7c).

Following durability testing in hydrogen peroxide oxidation (red squares), only minor losses in OER activity and ECA were observed. In formic acid oxidation (blue circles), however, OER mass activity losses significantly increased with increasing gas generation rates. Following the maximum stress test $(0.024 \mathrm{sccm})$, roughly half of the initial mass activity was lost, primarily due to declining ECA. In OER (green triangles), increasing mass activity losses occurred at higher gas generation rates. At moderate gas generation, these losses were driven by ECA loss; at higher rates, however, the mass activity losses were due to a combination of declining ECA and site-specific activity.

To understand the cause of Ir degradation, durability experiments in hydrogen peroxide oxidation (red squares), formic acid oxidation (blue circles), and OER (green triangles) were compared for: the potential that Ir was exposed to (Figure 8a); and the amount of Ir that dissolved (Figures $8 \mathrm{~b}$ and $8 \mathrm{c}$ ). Activity losses in formic acid oxidation and OER were likely due to the higher potential causing aggregation and dissolution (Figure 8a). Although formic acid oxidation has a low standard potential $(-0.11 \mathrm{~V}$ vs RHE), Ir nanoparticles were a poor catalyst and required significant overpotential to produce the high currents required in chronopotentiometry. When accelerated stress tests in formic acid produced significant loss (at high gas generation rates), the Ir nanoparticles (JM) were exposed to potentials greater than $1.5 \mathrm{~V}$ and likely participated in OER in addition to formic acid oxidation. Under these conditions, activity losses and Ir dissolution rates following formic acid oxidation were similar to the OER stress tests in the same potential window. In TEM, Ir nanoparticles that underwent durability to 1.5 and $1.6 \mathrm{~V}$ (13.5 h potential hold) were compared to the as-received material. Although most of the catalyst post-durability was similar in particle size to the as-received, there were occasional instances where much larger particles were observed, which may account for the ECA loss.

Half-cell and single-cell comparison.-MEAs were fabricated and tested to compare half-cell and single-cell MEA performances, and evaluate half-cell testing as a preliminary indicator of catalyst activity (Figure 9a). The single-cell MEA data is of particular interest in that only small losses in performance were observed when reducing the anode loading $75 \%$, from 0.4 (green squares) to $0.1 \mathrm{mg}_{\mathrm{Ir}} \mathrm{cm}^{-2}$ (blue squares, Figure $9 \mathrm{~b}$ ). The result appears to indicate that lowering the catalyst loading can improve Ir utilization and be used to reduce the cost of the catalyst layer. Differences in activity were observed between the RDE (red line) and MEA data, and there were several differences in collecting the data sets, including temperature (RDE at room temperature, MEA at $80^{\circ} \mathrm{C}$ ), internal resistance corrections (RDE was iR corrected, MEA was not), and catalyst loading (specified in Figure 9a). Although RDE experiments maintained a kinetic response at low potential, the fast generation and removal of oxygen bubbles at high potential created transport limitations and noise in the measured current, which may account for differences in RDE/MEA performance.

Durability of the low-loaded MEA (anode loading $0.1 \mathrm{mg}_{\mathrm{Ir}} \mathrm{cm}^{-2}$ ) was tested by cycling between 1.45 and $2.0 \mathrm{~V}(1.65-1.7 \mathrm{~V}$ when $\mathrm{iR}$ corrected, Figure 9c). MEA durability tests of the low-loaded anode were conducted for 10,000 (blue open squares) and 23,000 cycles 

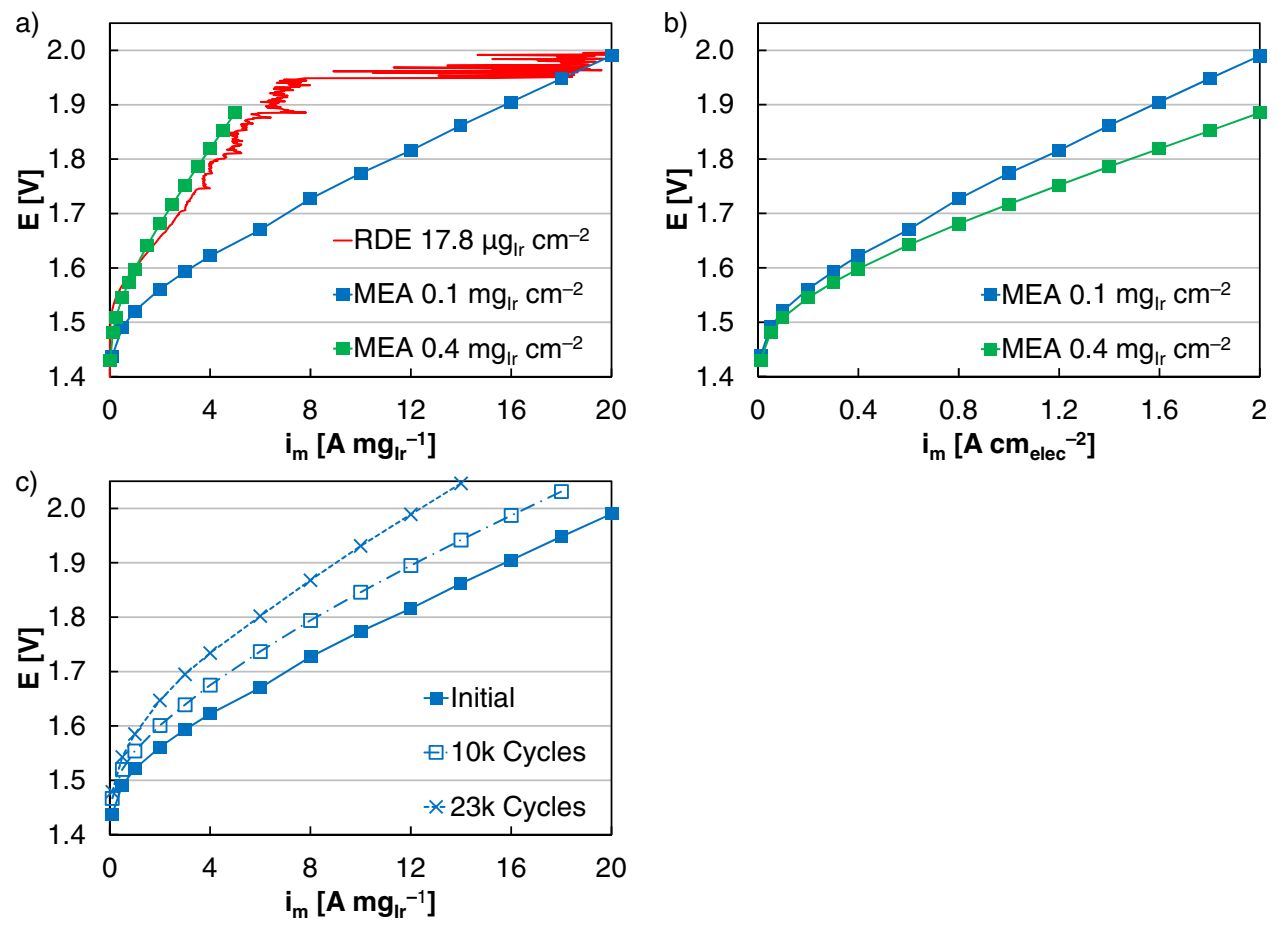

Figure 9. (a) Comparison of RDE and MEA performance at electrode loadings of $17.8 \mu \mathrm{g}_{\mathrm{Ir}} \mathrm{cm}^{-2}$ (RDE), 0.1 , and $0.4 \mathrm{mg}_{\mathrm{Ir}} \mathrm{cm}^{-2}$ (MEA anode). (b) MEA performance normalized to electrode area. (c) MEA $\left(0.1 \mathrm{mg}_{\mathrm{Ir}} \mathrm{cm}^{-2}\right)$ durability testing to 10,000 and 23,000 cycles, where a single cycle consisted of a $30 \mathrm{~s}$ hold at $1.45 \mathrm{~V}$, followed by a $30 \mathrm{~s}$ hold at $2.0 \mathrm{~V}$.

(blue crosses), or 6.9 and 16.0 days. Following 23,000 cycles (16.0 days), the MEA activity was approximately half of its initial (blue solid squares) performance. Similar losses were observed in RDE durability, but occurred at a lower potential $(1.5-1.6 \mathrm{~V}$, iR corrected) and during a shorter time frame $(13.5 \mathrm{~h})$. Durability losses to this extent were not observed using MEAs with a higher anode loading, although the Ir catalyst partially decayed due to agglomeration and migration (confirmed by TEM, data not shown). ${ }^{46}$ The results at $0.1 \mathrm{mg}_{\mathrm{Ir}} \mathrm{cm}^{-2}$ appear to indicate that durability is a concern in MEA performance, primarily at lower loadings. Continued efforts are needed to evaluate MEA durability and the applicability of accelerated stress tests in RDE and MEA testing to anticipated operating conditions. A consensus on durability testing protocols and on the expected performance of single-cell MEA durability also needs to be reached.

In today's commercial electrolysis, the cost of hydrogen production is dominated not by capital (catalyst) cost, but by the cost of electricity input. Electrolysis is typically performed continuously and with relatively high catalyst loadings. Our results suggest that under these conditions, durability losses due to catalyst degradation would be reduced. The relative steady rate of hydrogen production required from the system may also minimize durability losses associated with start-stop operation. In the future, to reach hydrogen production cost targets, electricity input costs will need to be addressed and will likely result in some sacrifice of capacity for the use of low cost, intermittent, renewable sources of electricity. As lower electricity costs are achieved, the capital cost will become a more significant contributor to overall costs, necessitating a reduction in catalyst loading to minimize the cost of the catalyst layer. Lower catalyst loadings are expected to increase concerns over Ir catalyst durability. Moreover, the use of intermittent electrons may accelerate durability losses through repeated start-stop operation. Although the data presented in this study begins to address mechanisms of Ir durability in RDE half-cells, continued efforts are needed at both the RDE and MEA scale to ascertain how ex-situ testing can be used to screen catalysts for MEA implementation and durability.

\section{Conclusions}

Ir nanoparticles were studied for OER activity and durability in half-cells and single-cells. Potential holds and cycles in RDE testing were used to probe Ir nanoparticle durability. At moderate potential $(1.4$ to $1.6 \mathrm{~V})$, losses were driven by particle growth; at higher potential $(\geq 1.8 \mathrm{~V})$, losses were due to Ir dissolution. Although the formation of gas bubbles may have affected the catalyst layer stability, accelerated stress tests in hydrogen peroxide and formic acid oxidation suggested that activity loss was primarily potential driven.

In RDE half-cells, large losses in OER mass activity and surface area, $50 \%$ and greater, were observed following accelerated stress tests at moderate potential. The durability of Ir nanoparticles in electolyzers has been less problematic than observed in RDE half-cells, and high Ir loadings in electrolyzer MEAs may mask durability losses. A continuing push for commercial competitiveness may force cost reduction and a decrease in the Ir loading in electrolyzer MEAs. With a reduction in the Ir MEA loading, the durability of Ir in OER will become increasingly vital and a necessary consideration in the design of OER catalysts.

\section{Acknowledgments}

Financial support was provided by the U. S. Department of Energy, SBIR/STTR program under contract \# DE-SC0007471 through Giner, Inc.

\section{References}

1. A. Milbrandt and M. Mann, in, U. S. Department of Energy Editor (2009).

2. R. Forgie, G. Bugosh, K. C. Neyerlin, Z. Liu, and P. Strasser, Electrochemical and Solid-State Letters, 13, B36 (2010).

3. K. Harrison, in, U. S. Department of Energy Editor (2010).

4. K. Harrison and M. Peters, in, U. S. Department of Energy Editor (2013).

5. M. J. N. Pourbaix, J. Van Muylder, and N. de Zoubov, Platinum Metals Review, 3, 100 (1959).

6. T. Reier, M. Oezaslan, and P. Strasser, ACS Catalysis, 2, 1765 (2012) 
7. S. Cherevko, S. Geiger, O. Kasian, N. Kulyk, J.-P. Grote, A. Savan, B. R. Shrestha, S. Merzlikin, B. Breitbach, A. Ludwig, and K. J. J. Mayrhofer, Catalysis Today, 262, 170 (2016).

8. S. Cherevko, A. R. Zeradjanin, A. A. Topalov, N. Kulyk, I. Katsounaros, and K. J. J. Mayrhofer, ChemCatChem, 6, 2219 (2014).

9. S. Kulandaisamy, J. P. Rethinaraj, S. C. Chockalingam, S. Visvanathan, K. V. Venkateswaran, P. Ramachandran, and V. Nandakumar, Journal of Applied Electrochemistry, 27, 579 (1997).

10. U. Kamachi Mudali, V. R. Raju, and R. K. Dayal, Journal of Nuclear Materials, 277, 49 (2000).

11. Y. Kamegaya, K. Sasaki, M. Oguri, T. Asaki, H. Kobayashi, and T. Mitamura, Electrochimica Acta, 40, 889 (1995).

12. A. de Oliveira-Sousa, M. A. S. da Silva, S. A. S. Machado, L. A. Avaca, and P. de Lima-Neto, Electrochimica Acta, 45, 4467 (2000).

13. R. Otogawa, M. Morimitsu, and M. Matsunaga, Electrochimica Acta, 44, 1509 (1998).

14. J. Cheng, H. Zhang, G. Chen, and Y. Zhang, Electrochimica Acta, 54, 6250 (2009).

15. F. I. Mattos-Costa, P. de Lima-Neto, S. A. S. Machado, and L. A. Avaca, Electrochimica Acta, 44, 1515 (1998).

16. R. Kötz and S. Stucki, Electrochimica Acta, 31, 1311 (1986).

17. M. H. Miles, E. A. Klaus, B. P. Gunn, J. R. Locker, W. E. Serafin, and S. Srinivasan, Electrochimica Acta, 23, 521 (1978).

18. R. Forgie, G. Bugosh, K. Neyerlin, Z. Liu, and P. Strasser, Electrochemical and Solid-State Letters, 13, B36 (2010).

19. M. V. ten Kortenaar, J. F. Vente, D. J. W. Ijdo, S. Müller, and R. Kötz, Journal of Power Sources, 56, 51 (1995).

20. A. Marshall, B. Børresen, G. Hagen, M. Tsypkin, and R. Tunold, Electrochimica Acta, 51, 3161 (2006).

21. K. C. Neyerlin, G. Bugosh, R. Forgie, Z. Liu, and P. Strasser, Journal of The Elec trochemical Society, 156, B363 (2009).

22. E. Tsuji, A. Imanishi, K.-i. Fukui, and Y. Nakato, Electrochimica Acta, 56, 2009 (2011).

23. R. Kötz, S. Stucki, D. Scherson, and D. M. Kolb, Journal of Electroanalytical Chemistry and Interfacial Electrochemistry, 172, 211 (1984).

24. I. C. Man, H.-Y. Su, F. Calle-Vallejo, H. A. Hansen, J. I. Martínez, N. G. Inoglu, J. Kitchin, T. F. Jaramillo, J. K. Nørskov, and J. Rossmeisl, ChemCatChem, 3, 1159 (2011)

25. R. De Levie, Journal of Electroanalytical Chemistry, 476, 92 (1999)
26. H. Cavendish, Philosophical Transactions of the Royal Society of London, 74, 119 (1784).

27. A. Paets van Troostwijk and J. Deiman, J. Phys, 35, 369 (1789).

28. H. A. Gasteiger, S. S. Kocha, B. Sompalli, and F. T. Wagner, Applied Catalysis B: Environmental, 56, 9 (2005).

29. S. M. Alia, S. Pylypenko, K. C. Neyerlin, S. S. Kocha, and B. S. Pivovar, ECS Transactions, 69, 883 (2015).

30. S. P. Kounaves and J. Buffle, Journal of The Electrochemical Society, 133, 2495 (1986).

31. S. M. Alia, K. E. Hurst, S. S. Kocha, and B. S. Pivovar, Journal of The Electrochemical Society, 163, F3051 (2016)

32. K. Shinozaki, J. W. Zack, R. M. Richards, B. S. Pivovar, and S. S. Kocha, Journal of The Electrochemical Society, 162, F1144 (2015).

33. M. Uchimura, S. Sugawara, Y. Suzuki, J. Zhang, and S. S. Kocha, ECS Transactions, 16, 225 (2008).

34. S. S. Kocha, in Polymer Electrolyte Fuel Cell Degradation, M. Mench, E. C. Kumbur, and T. N. Veziroglu Editors, p. 89, Academic Press, Waltham (2011).

35. A. Minguzzi, C. Locatelli, O. Lugaresi, E. Achilli, G. Cappelletti, M. Scavini, M. Coduri, P. Masala, B. Sacchi, and A. Vertova, ACS Catalysis, 5, 5104 (2015).

36. A. Minguzzi, O. Lugaresi, E. Achilli, C. Locatelli, A. Vertova, P. Ghigna, and S. Rondinini, Chemical Science, 5, 3591 (2014).

37. P. Steegstra, M. Busch, I. Panas, and E. Ahlberg, The Journal of Physical Chemistry $C, \mathbf{1 1 7}, 20975$ (2013).

38. A. Minguzzi, O. Lugaresi, C. Locatelli, S. Rondinini, F. D'Acapito, E. Achilli, and P. Ghigna, Analytical chemistry, 85, 7009 (2013).

39. M. Pourbaix, Atlas of electrochemical equilibria in aqueous solutions, National Association of Corrosion Engineers, Houston, Texas (1974).

40. V. G. Prabhu, L. R. Zarapkar, and R. G. Dhaneshwar, Electrochimica Acta, 26, 725 (1981).

41. S. B. Hall, E. A. Khudaish, and A. L. Hart, Electrochimica Acta, 43, 579 (1998).

42. S. B. Hall, E. A. Khudaish, and A. L. Hart, Electrochimica Acta, 43, 2015 (1998).

43. S. Fierro, L. Ouattara, E. H. Calderon, E. Passas-Lagos, H. Baltruschat, and C. Comninellis, Electrochimica Acta, 54, 2053 (2009).

44. G. Bianchi, F. Mazza, and T. Mussini, Electrochimica Acta, 7, 457 (1962).

45. A. Capon and R. Parsons, Journal of Electroanalytical Chemistry and Interfacial Electrochemistry, 44, 239 (1973).

46. H. Xu, B. Rasimick, K. L. More, S. M. Alia, and B. S. Pivovar, in 228th ECS Meeting, p. 1516, Phoenix, AZ (2015). 